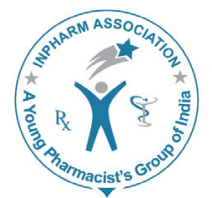

\title{
Assessment of Depression as Comorbidity in Diabetes Mellitus Patients using Beck Depression Inventory II (BDI II) Scale
}

\author{
Atta Abbas ${ }^{1,2,3,4, *}$, Hira Nasir ${ }^{1}$, Anum Zehra ${ }^{1}$, Anum Noor ${ }^{1}$, Fareeha Abdul \\ Jabbar $^{1}$ and Bisma Siddqui ${ }^{1}$ \\ ${ }^{1}$ Faculty of Pharmacy, Ziauddin University, Karachi, Pakistan
}

${ }^{2}$ Hamdard Institute of Pharmaceutical Sciences, Hamdard University, Karachi, Pakistan

${ }^{3}$ Department of Pharmacy, Clifton Hospital, Karachi, Pakistan

${ }^{4}$ The Royal Pharmaceutical Society of Great Britain, London, United Kingdom

\begin{abstract}
Objective: The objective was to assess depression as comorbidity among patients of diabetes mellitus (DM) using Beck Depression Inventory II (BDI II) scale. Materials and Method: A cross sectional survey was conducted in Pakistan for 3 months targeting patients of diabetes mellitus DM and assessing their depression as a comorbidity using BDI II questionnaire. Data analysis was carried out using SPSS version 20. Descriptive statistics, cross tabulation and Chi square $\left(\mathrm{X}^{2}\right)$ tests were employed. Results: Majority of the target group was normal $(\mathrm{N}=58,28 \%)$ while a quarter of the sample suffers from mild depression ( $N=54,26.1 \%)$. Some suffered from moderate depression $(N=43,20.8 \%)$ followed by a tenth of segment who suffered from severe depression $(\mathrm{N}=20,9.7 \%)$. Few were reported to suffer from extreme episodes of depression $(\mathrm{N}=4,1.9 \%)$. The depression was also statistically associated with patients' BMI $(<0.05)$, disease duration $(<0.01)$, family history $(<0.01)$ and glycated haemoglobin $\mathrm{Hb}_{\mathrm{A1C}}(<0.01)$. Conclusion: Likelihood of suffering from depression in $\mathrm{DM}$ is high. Modifiable factors i.e. BMI, HBA1c, etc. and non modifiable factors of DM such as genetic predisposition and disease duration play an important role in occurrence of depression as comorbidity. Educating the patients about DM can prove effective in dealing with the disease and its complications since patients will be prepared and be taught aggressive self management which may also prove helpful in managing comorbid depression.
\end{abstract}

Key words: Beck Depression Inventory(BDI), Depression, Diabetes Mellitus, Pakistan, Patients.

\begin{tabular}{|c|c|}
\hline \multicolumn{2}{|c|}{ Access this article online } \\
\hline Journal Sponsor & \multirow[b]{2}{*}{$\begin{array}{l}\text { Website: } \\
\text { www.jyoungpharm.org }\end{array}$} \\
\hline \multirow{2}{*}{ www.phcog net } & \\
\hline & $\begin{array}{l}\text { DOI: } \\
\text { 10.5530/jyp.2015.3.11 }\end{array}$ \\
\hline
\end{tabular}

\section{INTRODUCTION}

*Address for correspondence:

Mr. Atta Abbas, Department of Pharmacy, Clifton Hospital, F 175-1, Block 5, Clifton, 75600, Karachi, Pakistan,

Phone No :0092-321-2643077,0097-150-4719421.E-mail : bg33bd@student.sunderland.ac.uk 


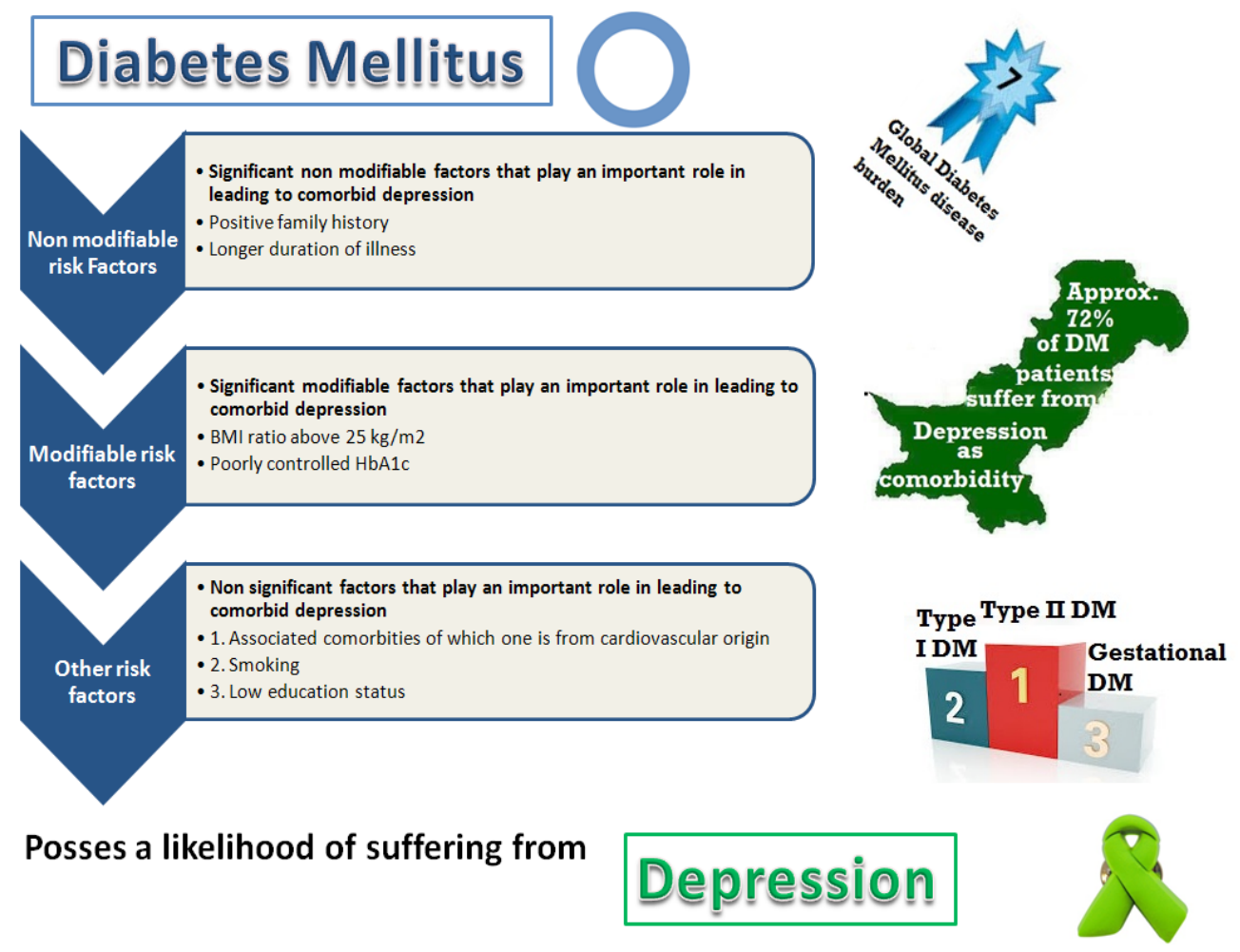

Graphica Abstract

Gestational Diabetes which is pregnancy induced. Certain micro vascular and macro vascular complications are found to be associated with diabetes and the diabetic patients are at a higher risk of developing such ramifications. Macro vascular complications arise from the scathe of larger blood vessels and include cardiovascular disease CVD and peripheral vascular disease PVD while damage to smaller blood vessels contributes to the development of micro vascular complications which include retinopathy, nephropathy and neuropathy. ${ }^{1}$

It is a widely acknowledged fact that diabetic individuals are more vulnerable to infections of lower extremities, urinary tract infections UTIs and fungal infections due to compromised immune system. Hypertension, dyslipidemia, obesity and depression are the comorbidities most commonly anticipated in patients with poor glycemic control. Various psychological, social and physical disabilities are involved which not only aggravate the disease state but may also lead to compromised quality of life. The degree of associated complications is further hyperbolised if depression is found to co-exist with DM.,3

A close association has been found between depression and peripheral neuropathy. Moreover, depression is commonly observed in patients suffering from diabetic neuropathy. ${ }^{4}$ However, depression is not considered an important factor, often ignored and left untreated. ${ }^{5}$ To demonstrate the prevalence of depression among diabetic individuals and to identify the various risk factors associated, several epidemiological studies have been conducted which concluded that various clinical, behavioural and demographic factors tend to be involved in the exacerbation of disease. ${ }^{6,7}$ The association of such risk factors with DM has been proven and verified continuously at several occasions. Female gender, younger age, lower education status, poverty, rigorousness of diabetes, duration of illness, elevated $\mathrm{Hb}_{\mathrm{Alc}}$ levels, smoking and obesity are the highlighted factors that are proven to be an ultimate risk for the correlation..$^{8-11}$

The association of depression with DM is seen as a major burden on the patients' health and it is subject to further investigation. One of the possible explanations to the association is focused on the management of DM which might be stressful and could lead to symptoms of depression. DM can cause complications and health problems that may worsen symptoms of depression. ${ }^{4}$ Furthermore, in case to type I DM, studies propose that it triggers a hormone that causes depression. For instance, cytokines, interleukins and tumor necrosis factor alpha $(\mathrm{TNF}-\alpha)$ are increased. ${ }^{12}$ In addition to this, studies also report that frequent fluctuations in blood sugar levels in women with type II DM are associated with a lower quality 
of life and negative moods. ${ }^{3,4}$ In light of studies conducted on the subject, it can be said that depression and diabetes are linked to each other and better management of DM can reduce the likelihood of experiencing an episode of depression.

The story of Pakistan continues to haunt as the country has a large diabetic population making it the $7^{\text {th }}$ largest in the world. ${ }^{13,14}$ The barriers to adequate management of diabetes include poverty, stigmatization to the disease, socio-economic status and low education. ${ }^{6,7}$ Such factors coupled with an incapacitated health care system is leading to further increase the disease burden at a fast pace. ${ }^{15}$ Studies conducted in Pakistan reported presence of anxiety and depression among type II DM patients and called for aggressive management and pharmacotherapy of DM. The investigators further proposed more studies to be conducted in the said regard. ${ }^{16-18}$

The present study incorporated patients with type I, II and Gestational Diabetes, recorded their information and assessed their depression status using Beck Depression Inventory BDI II scale.

\section{MATERIALS AND METHODS}

A cross sectional survey was conducted in Pakistan for 3 months i.e. from June 2014 to August 2014 with the aim of assessing depression as a comorbidity in patients of diabetes mellitus DM. The target population was the diabetic patients and they were accessed in hospitals as well as at homes by convenience sampling technique. The inclusion and exclusion criteria were set as all those in patients and out patients who were reported to suffer from the 3 phenotypes of diabetes mellitus DM namely type I, II and gestational diabetes with an established diagnosis were included and all other patients and those without established DM diagnosis were excluded from the study. The research instrument consisted of a structured questionnaire in English containing close ended questions related to the demographic, professional and disease information supplemented with Beck Depression Inventory II scale questionnaire employed for documenting depression. The patients who had difficulty in filling of questionnaires were assisted by data gatherers and interpreters. The study instrument was piloted on a number of individuals and validated by for suitability. The questionnaire was piloted on 15 patients and it took 7-10 minutes to fill the questionnaire. The team of experts included university professors and clinical pharmacists. The patients were informed and a written consent was obtained before handing the questionnaire. The responses of the patients were documented and analyzed by SPSS v 20 (Statistical Package for Social Sciences version 20). The data was expressed as sample number $(N)$ and percentage $(\%)$. The association of demographic variables and BDI II Scores was analyzed by Chi square $\left(X^{2}\right)$ test and expressed in terms of significant value ( $P$ value) less than 0.05 . The hypothetical results were derived by running the Chi square $X^{2}$ test for association and documenting the expected values which are theoretically calculated to quantitatively demonstrate a non significant association or no association between variables under investigation i.e. ( $P$ value greater than 0.05) against which observed counts were compared. Figures were included where appropriate to demonstrate a graphical comparison between the actual and expected counts of variables in results section. The demographic

\begin{tabular}{|c|c|c|}
\hline Attributes & Sample (N) & Percentage (\%) \\
\hline \multicolumn{3}{|l|}{ Age } \\
\hline $0-18$ years & 6 & 2.9 \\
\hline 19-45years & 62 & 30 \\
\hline Above 45 years & 139 & 67.1 \\
\hline Total & 207 & 100 \\
\hline \multicolumn{3}{|l|}{ Gender } \\
\hline Male & 91 & 44 \\
\hline Female & 116 & 56 \\
\hline Total & 207 & 100 \\
\hline \multicolumn{3}{|l|}{ Education } \\
\hline Uneducated & 26 & 12.5 \\
\hline Secondary (Matriculation) & 43 & 20.8 \\
\hline $\begin{array}{l}\text { Higher Secondary } \\
\text { (Intermediate) }\end{array}$ & 62 & 30 \\
\hline Graduate & 76 & 36.7 \\
\hline Total & 207 & 100 \\
\hline \multicolumn{3}{|l|}{ Social Status } \\
\hline Married & 150 & 72.5 \\
\hline Single & 40 & 19.3 \\
\hline Divorced & 17 & 8.2 \\
\hline Total & 207 & 100 \\
\hline \multicolumn{3}{|c|}{ Body Mass Index BMI $\left(\mathrm{Kg} / \mathrm{m}^{2}\right)$} \\
\hline Less than 18 & 7 & 3.3 \\
\hline Between 18 to 25 & 72 & 34.8 \\
\hline Between 25 to 30 & 72 & 34.8 \\
\hline Greaterthan 30 & 56 & 27.1 \\
\hline Total & 207 & 100 \\
\hline \multicolumn{3}{|l|}{ Smoking habits } \\
\hline Rarely smoke & 24 & 11.6 \\
\hline Regular & 33 & 15.9 \\
\hline Chronic smoker & 19 & 9.2 \\
\hline Non smoker & 131 & 63.3 \\
\hline Total & 207 & 100 \\
\hline \multicolumn{3}{|l|}{ Patient type } \\
\hline Inpatient & 65 & 31.4 \\
\hline Outpatient & 142 & 68.6 \\
\hline Total & 207 & 100 \\
\hline
\end{tabular}

Journal of Young Pharmacists Vol 7 • Issue $3 \bullet$ Jul-Sep 2015 


\begin{tabular}{ccc}
$\begin{array}{c}\text { Table 2: Summary of professional information } \\
\text { Attributes }\end{array}$ & Sample (N) & Percentage (\%) \\
$\begin{array}{c}\text { Professional Information } \\
\text { Working }\end{array}$ & 94 & 45.4 \\
Nonworking & 113 & 54.6 \\
Total & 207 & 100 \\
Nature of work & & \\
\hline Jobseekers & 9 & 4.3 \\
\hline Medical & 2 & 1 \\
\hline Industrial & 3 & 1.5 \\
\hline Retired & 13 & 6.6 \\
\hline Teacher & 11 & 5.3 \\
\hline Student & 3 & 1.5 \\
\hline Banker & 9 & 4.3 \\
\hline Private Business & 26 & 12.6 \\
\hline House hold & 12 & 5.8 \\
\hline Public sector & 1 & 0.5 \\
\hline Unskilledlabor & 4 & 2 \\
\hline Nonworking & 113 & 54.6 \\
\hline Total & 207 & 100
\end{tabular}

variables of patients were tested with same by comparing the expected and actual counts and finding out the significance which was accepted at $P$-value $<0.05$. The study was approved by the Department of Pharmacy Practice, Faculty of Pharmacy, Ziauddin University, Pakistan and Ethical Committee of Research Review Board, Clifton Hospital, Pakistan.

\section{RESULTS}

A total of 207 patients' responses were available. The results are explained in the following sections:

- Demographic information

- Professional information

- Disease information

- Beck depression inventory II (BDI II) scores and their interpretation

- Association of variables with BDI II Scores

\section{Demographic information}

The survey encountered majority of the patient above the age of 45 years $(\mathrm{N}=139,67.1 \%)$ followed by a third between $19-45$ years $(\mathrm{N}=62,30 \%)$ and few below the age of 18 years $(\mathrm{N}=6,2.9 \%)$. In terms of the gender, majority were the females $(\mathrm{N}=116,56 \%)$ followed by the males $(\mathrm{N}=91$, $44 \%$ ). To the question of education, a high proportion of the target segment comprised of patients with education level up to graduation $(\mathrm{N}=76,36.7 \%)$ followed by those educated up to higher secondary or Intermediate $(\mathrm{N}=62$, $30 \%$ ). Some of the patients were educated up to secondary education or Matriculation (N=43, 20.8\%) and few were uneducated $(\mathrm{N}=26,12.6 \%)$. The social status reported that majority of patients were married $(\mathrm{N}=150,72.5 \%)$ while some were single $(\mathrm{N}=40,19.3 \%)$ and very few individuals were divorced $(\mathrm{N}=17,8.2 \%)$.

The Body Mass Index BMI ratio of patients demonstrated that almost a third of the diabetic individuals possess the BMI in the range of $18-25 \mathrm{~kg} / \mathrm{m}^{2}(\mathrm{~N}=72,34.8 \%)$ and 25 $30 \mathrm{~kg} / \mathrm{m}^{2}(\mathrm{~N}=72,34.8 \%)$, some patients possess the BMI ratio of greater than $30 \mathrm{~kg} / \mathrm{m}^{2}(\mathrm{~N}=56,27.1 \%)$ while only a small proportion of diabetic patients fall in the BMI range of less than $18 \mathrm{~kg} / \mathrm{m}^{2}(\mathrm{~N}=7,3.4 \%)$. The smoking habits of these patients revealed that majority of patients were non-smokers $(\mathrm{N}=131,63.3 \%)$ followed by those who smoked regularly $(\mathrm{N}=33,15.9 \%)$. Some of the patients fell in the category of rare smokers $(\mathrm{N}=24,11.6 \%)$ and a negligible proportion of diabetic patients were chronic smokers $(\mathrm{N}=19,9.2 \%)$. The demographic information of patients also reported that out patients were seen in majority $(\mathrm{N}=142,68.6 \%)$ and in patients were in minority $(\mathrm{N}=65,31.4 \%)$. The results of the demographic findings of patients are summarized in Table 1.

\section{Professional information}

The survey found out that slightly less than half of the target segment worked to earn their bread ( $\mathrm{N}=94,45.4 \%$ ). However, more than half of the target segment did not work $(\mathrm{N}=113,54.6 \%)$. A small proportion of patients were unemployed and appeared searching for job ( $\mathrm{N}=9,4.3 \%)$. However, some were running their private businesses $(\mathrm{N}=26,12.6 \%)$ while some had been retired $(\mathrm{N}=13,6.6 \%)$ followed by a small number of patients who were indulged in household work $(\mathrm{N}=12,5.8 \%)$. Some patients were found to be associated with the teaching profession $(\mathrm{N}=11$, $5.3 \%$ ) while some were bankers $(\mathrm{N}=9,4.3 \%)$ and a small proportion of patients were unskilled labors $(\mathrm{N}=4,2 \%)$ followed by students $(\mathrm{N}=3,1.5 \%)$ and those working in industrial sector $(\mathrm{N}=3,1.5 \%)$. Few patients were medical professionals $(\mathrm{N}=2,1 \%)$ and were seen working in public sector $(\mathrm{N}=1,0.5 \%)$. The results of all the professional information is summarized in Table 2.

\section{Disease information}

The data thus recorded confirmed majority of the target sample to suffer from Type $2 \mathrm{DM}(\mathrm{N}=171,82.6 \%)$ followed by patients with Type $1 \mathrm{DM}(\mathrm{N}=23,11.1 \%)$ and Gestational Diabetes (N=13, 6.3\%). The data also revealed that majority of patients were those who were suffering from DM for less than 5 years $(\mathrm{N}=107,51.7 \%)$ followed by those who were suffering from DM for about 5 to 10 years $(\mathrm{N}=66,31.9 \%)$ and those who had diabetes for more than 10 years $(\mathrm{N}=34,16.4 \%)$. Family history revealed that 
Abbas, et al.: Assessment of Depression as Comorbidity in Diabetes Mellitus Patients

\begin{tabular}{|c|c|c|}
\hline Attributes & Sample (N) & Percentage (\%) \\
\hline \multicolumn{3}{|l|}{ Type of DM } \\
\hline Type 1 DM & 23 & 11.1 \\
\hline Type2DM & 171 & 82.6 \\
\hline GestationalDiabetes & 13 & 6.3 \\
\hline Total & 207 & 100 \\
\hline \multicolumn{3}{|l|}{ Duration of disease } \\
\hline Less than 5 years & 107 & 51.7 \\
\hline Between 5 to 10 years & 66 & 31.9 \\
\hline Above 10 years & 34 & 16.4 \\
\hline Total & 207 & 100 \\
\hline \multicolumn{3}{|l|}{ Family history } \\
\hline Positive & 137 & 66.2 \\
\hline Negative & 70 & 33.8 \\
\hline Total & 207 & 100 \\
\hline \multicolumn{3}{|l|}{$\mathrm{Hb}_{\mathrm{A} 1 \mathrm{C}}$ history } \\
\hline Less than $6 \%$ & 66 & 31.9 \\
\hline $\begin{array}{c}\text { Between } 6.5 \% \text { to } \\
7.5 \%\end{array}$ & 111 & 53.6 \\
\hline Greater than $7.5 \%$ & 30 & 14.5 \\
\hline Total & 207 & 100 \\
\hline \multicolumn{3}{|l|}{ Co morbidity } \\
\hline No co-morbidity & 91 & 44 \\
\hline Endocrine & 11 & 5.3 \\
\hline Gastrointestinal & 5 & 2.4 \\
\hline Cardiovascular & 58 & 28 \\
\hline Musculoskeletal & 5 & 2.4 \\
\hline CNS & 3 & 1.4 \\
\hline Pulmonary & 3 & 1.4 \\
\hline Skin related & 2 & 1 \\
\hline $\begin{array}{l}\text { Cardiovascular }+ \\
\text { Pulmonary }\end{array}$ & 4 & 2 \\
\hline $\begin{array}{l}\text { Cardiovascular+ } \\
\text { Musculoskeletal }\end{array}$ & 9 & 4.4 \\
\hline $\begin{array}{c}\text { Cardiovascular + } \\
\text { CNS }\end{array}$ & 2 & 1 \\
\hline $\begin{array}{l}\text { Cardiovascular + } \\
\text { Endocrine }\end{array}$ & 11 & 5.3 \\
\hline $\begin{array}{l}\text { Cardiovascular+ } \\
\text { Gastrointestinal }\end{array}$ & 3 & 1.4 \\
\hline Total & 207 & 100 \\
\hline
\end{tabular}

majority of patients were positive i.e. disease was running in family lineage $(\mathrm{N}=137,66.2 \%)$ followed by a small number of patients who had a negative family history of $\mathrm{DM}(\mathrm{N}=70,33.8 \%)$. The glycosylated hemoglobin levels $\mathrm{Hb}_{\mathrm{A1c}}$ of majority of target segment fell in the range $6.5 \%$ to $7.5 \%(\mathrm{~N}=111,53.6 \%)$ while some patients had $\mathrm{Hb}_{\mathrm{A1c}}$ value less than $6 \%(\mathrm{~N}=66,31.9 \%)$ and few possessed $\mathrm{Hb}_{\mathrm{Alc}}$ greater than $7.5 \%(\mathrm{~N}=30,14.5 \%)$.

The survey also ascertained that majority of patients were devoid of any associated co-morbidity ( $N=91,44 \%)$ while a sizeable proportion of patients were found to be suffering from co-morbid cardiovascular diseases $(\mathrm{N}=58$,
Table 4: Summary of BDI II Scores and their interpretation

$\begin{array}{cccc}\text { Attributes } & \text { Interpretation } & \begin{array}{c}\text { Sample } \\ (\mathbf{N})\end{array} & \begin{array}{c}\text { Percentage } \\ (\%)\end{array} \\ \begin{array}{cccc}\text { Beck Depression Inventory II Scores } \\ \text { Between 1 to 10 }\end{array} & \text { Normal } & 58 & 28 \\ \text { Between 11 to 16 } & \text { Mild depression } & 54 & 26.1 \\ \text { Between 17 to 20 } & \begin{array}{c}\text { Borderline clinical } \\ \text { depression }\end{array} & 28 & 13.5 \\ \text { Between 21 to 30 } & \text { Moderate depression } & 43 & 20.8 \\ \text { Between31 to 40 } & \text { Severe depression } & 20 & 9.7 \\ \text { Above 40 } & \text { Extreme depression } & 4 & 1.9 \\ \text { Total } & & \mathbf{2 0 7} & \mathbf{1 0 0}\end{array}$

$28 \%)$ followed by those with endocrine alone and in combination with cardiovascular disorders each $(\mathrm{N}=11$, $5.3 \%$ ). In some patients a combination of cardiovascular and musculoskeletal disorders were found to coexist $(\mathrm{N}=9$, $4.4 \%$ ) while in some, gastrointestinal and musculoskeletal diseases were found as a co-morbidity $(\mathrm{N}=5,2.4 \%)$ followed by individuals with cardiovascular and pulmonary diseases together $(\mathrm{N}=4,2 \%)$. CNS, pulmonary and cardiovascular + GI disorders were also found as a co-morbid condition in few individuals $(\mathrm{N}=3,1.4 \%)$ followed by skin disorders and cardiovascular $+\mathrm{CNS}$ disorders each $(\mathrm{N}=2,1 \%)$. The results are summarized in Table 3.

Beck depression inventory II (BDI II) scores and their interpretation The patients were given BDI II scaling questionnaires and their scores were recorded. The results demonstrated that the majority of the target group was normal $(\mathrm{N}=58$, $28 \%$ ) while a quarter suffers from mild depression $(\mathrm{N}=54$, $26.1 \%$ ). A fifth suffered from moderate depression ( $N=43$, $20.8 \%$ ) followed by a tenth who suffered from severe depression $(\mathrm{N}=20,9.7 \%)$. Few were reported to suffer from extreme episodes of depression $(\mathrm{N}=4,1.9 \%)$. The summary of the results is expressed in Table 4.

\section{Association of variables with BDI II Scores}

The association of variables was calculated by Chi square $X^{2}$ test for association and significance was accepted at $\mathrm{P}$ values less than 0.05 . The significant association was further demonstrated in the form of a graphical representation containing observed and expected counts of variables under investigation.

\section{Association of BMI with BDI II Score}

It was observed that the variables were associated with the BDI II Scores. The variable of Body mass index BMI of patients was found to be associated with the BDI II Score with statistical significance $(P$ value $<0.05)$. Patients with a BMI between 19 to $25 \mathrm{~kg} / \mathrm{m}^{2}$ with BDI II Score interpretation of being normal were observed more in number as compared to the hypothetic value $(\mathrm{N}=27$ 


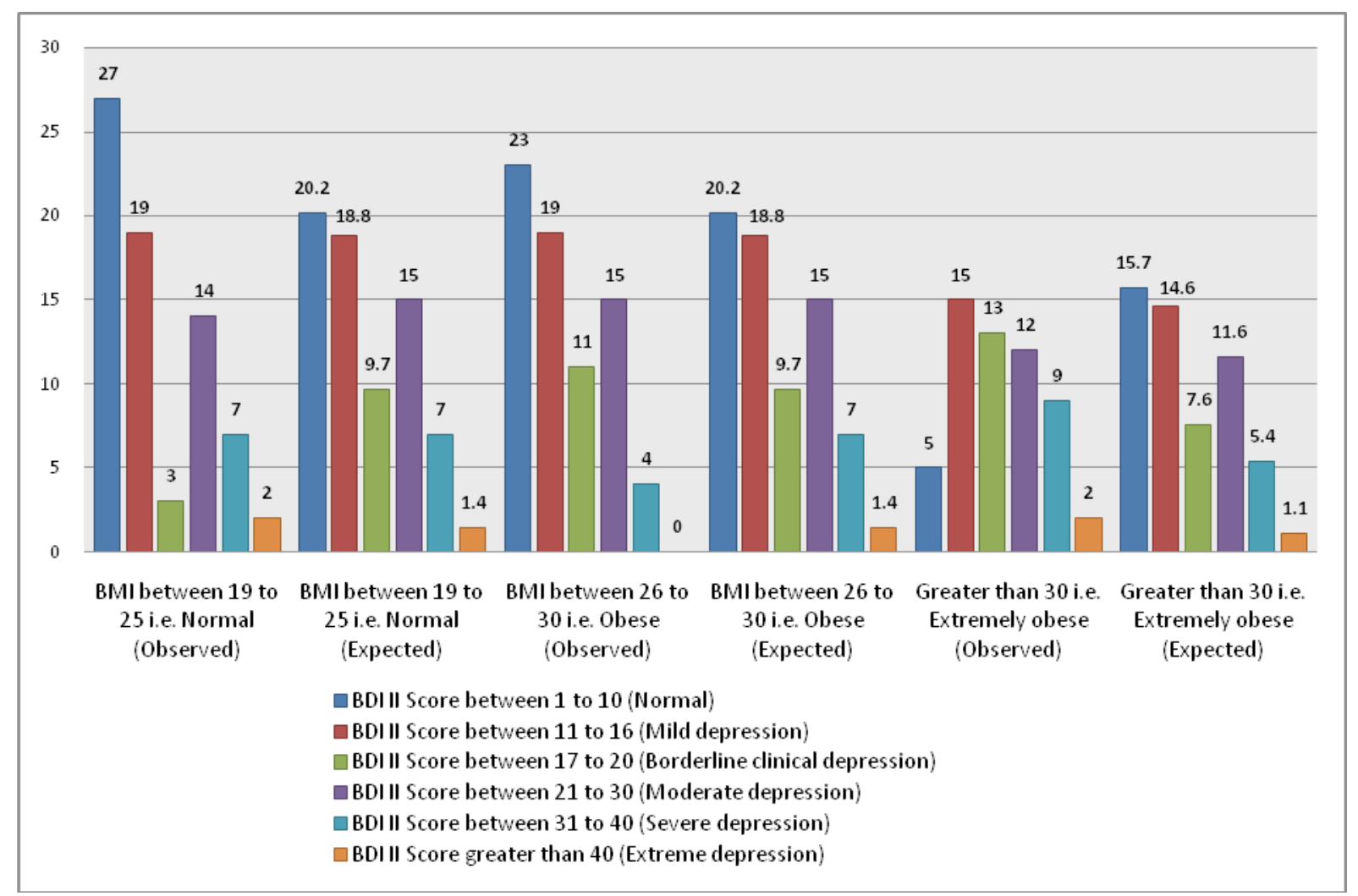

Figure 1: Association of BMI with BDI II Score

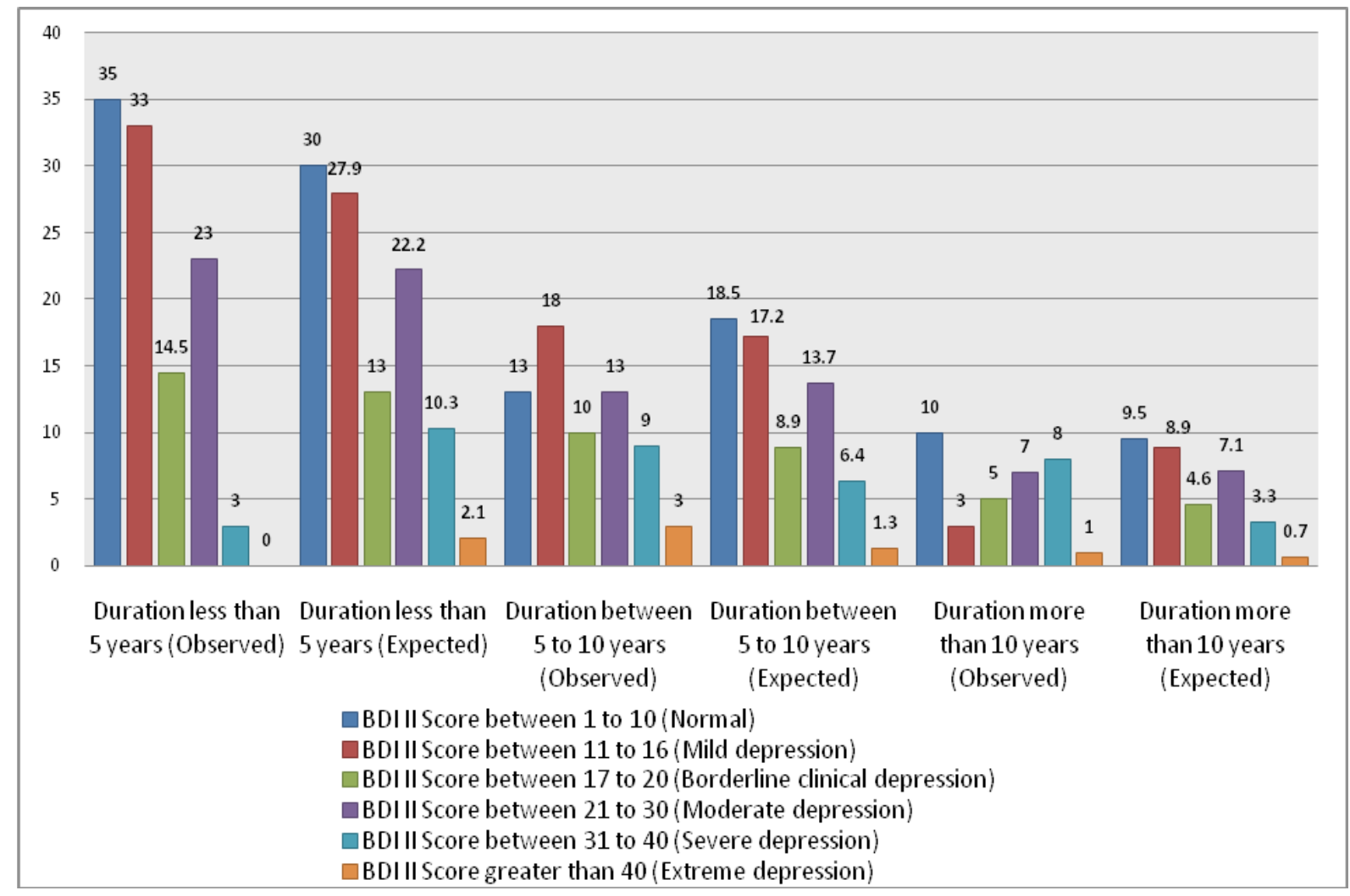

Figure 2: Association of disease duration with BDI II Scores 


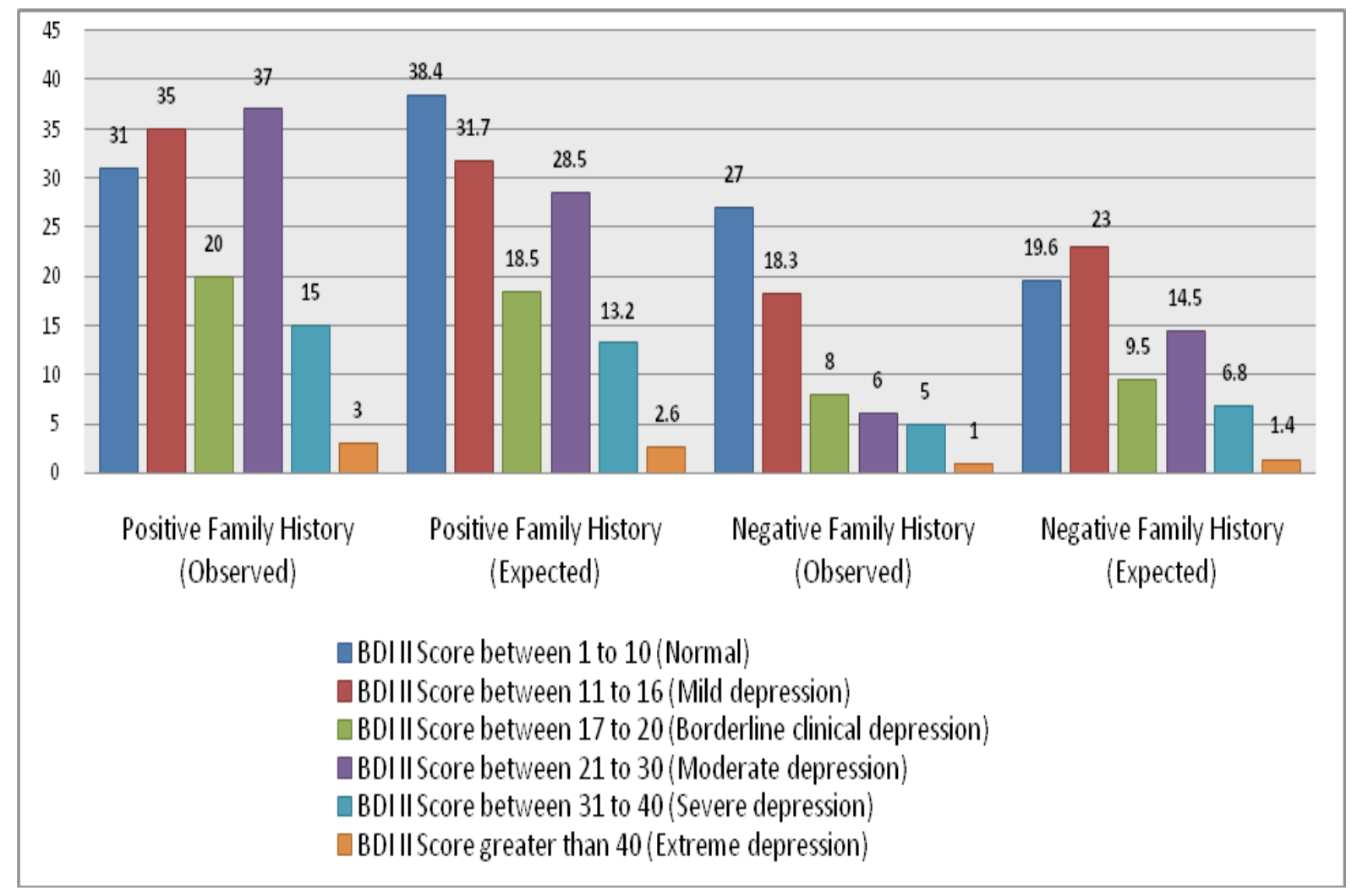

Figure 3: Association of family history with BDI II Scores

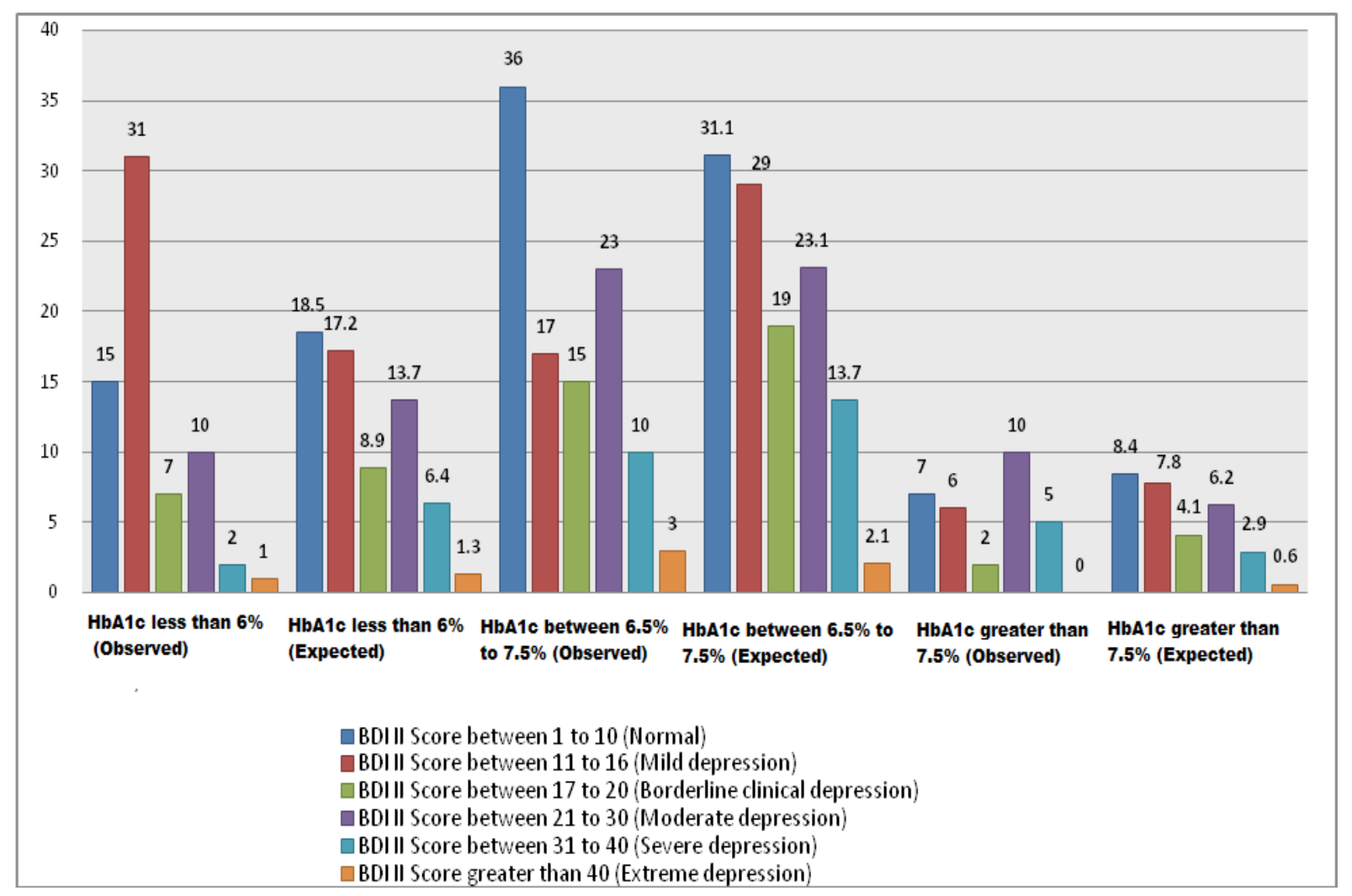

Figure 4: Association of HbA1c levels with BDI II Scores 


Table 5: Summary of association of variables with BDI II
Scores
$\begin{array}{cc}\text { Association with BDI II Score } & \text { P value } \\ \text { BMI } & <0.05 \\ \text { Duration of disease } & <0.01 \\ \text { Family History } & <0.01 \\ \mathrm{Hb}_{\mathrm{A} 1 \mathrm{c}} & <0.01\end{array}$

Observed, $\mathrm{N}=20.2$, Expected). However, the number of normal patients declined as the BMI increased i.e. 26 to $30 \mathrm{~kg} / \mathrm{m}^{2}$ ( $\mathrm{N}=23$ Observed, $\mathrm{N}=20.2$ Expected) and further dropped down to 5 with BMI greater than $30 \mathrm{~kg} /$ $\mathrm{m}^{2}$. $(\mathrm{N}=5$ Observed, $\mathrm{N}=15.7$ Expected). At the same time, the number of patients with BDI II Score interpretation of mild, moderate and severe depression increased with increasing BMI which arithmetically reconfirms the statistical association. The association is graphically demonstrated in Figure 1.

Association of disease duration with BDI II Scores

Furthermore, the duration of disease was also reported to be significantly associated with the BDI II Scores. ( $P$ value $<0.01$ ) It was observed that the number of patient suffering from DM since 5 years or less and with normal interpretation of BDI II Score was more as compared to the hypothetical expected count $(\mathrm{N}=35$ Observed, $\mathrm{N}=30$ Expected). However, those with DM between 5 years to 10 years revealed a contrasting picture as normalcy dropped more than what was expected $(\mathrm{N}=13$ Observed, $\mathrm{N}=18.5$ Expected). However, different graph was seen for those with DM for more than 10 years as the normal numbers observed were identical to expected numbers. ( $\mathrm{N}=10$ Observed, $\mathrm{N}=9.5$ Expected). Similarly, the trend of having mild, moderate and severe depression increased with duration of disease between 5 years to 10 years and identical for observed and expected in those with duration of disease for more than 10 years. This association revealed that depression is minimal in patients with newly acquired DM i.e. less than 5 years but aggravates the most between 5 to 10 years of DM. However, it stagnates in patients with a long acquired DM for more than 10 years. The association is graphically demonstrated in Figure 2.

\section{Association of family history with BDI II Scores}

The association of family history of DM patients with their BDI II Scores proved to be a significant one. (P value $<0.01$ ) The patients who appeared to be positive for the genetic predisposition of DM with normal interpretation for BDI II Score were observed to be less in number as compared to the expected ( $\mathrm{N}=31$ Observed, $\mathrm{N}=38.4$ Expected). At the same time, the number of patients with other severities of depression and positive family history were observed to be more in number than expected numbers. Contrastingly, the patients with family history negative for DM and normal interpretations of BDI II Scores were more in number as compared to the expected ones $(\mathrm{N}=27$ Observed, $\mathrm{N}=19.6$ Expected). The number of patients with family history negative for DM and having different severities of depression were observed to be less in number as compared to the hypothetical expected count. This association reveals the fact that the patients with DM having a risk factor of genetic predisposition for the disease are more prone to suffer from depression as compared to those having no genetic predisposition. The result of this association is graphical expressed in Figure 3.

Association of $\mathrm{Hb}_{\mathrm{Alc}}$ of patients with $\mathrm{BDI} / 1 \mathrm{~S}$ Scores

The association of glycated hemoglobin of patients with BDI II Scores was very significant. (P value $<0.01$ ) The patients with $\mathrm{Hb}_{\mathrm{A1c}}$ levels i.e. between $6.5 \%$ to $7.5 \%$ having normal interpretation of BDI II Score was observed to be more in number as compared to the hypothetical expected count. ( $\mathrm{N}=36$ Observed, $\mathrm{N}=31.1$ Expected) The observed count of such patients with different severities of depression was also lower than expected. In case of those patients who had $\mathrm{Hb}_{\mathrm{Alc}}$ level of less than 6\%; normal patients without depression were observed to be less in number as compared to hypothetical expected count. ( $\mathrm{N}=15$ Observed, $\mathrm{N}=18.5$, Expected) However, patients with BDI II Score interpretation of mild depression observed to be more than expected. ( $N=31$ Observed, $\mathrm{N}=17.2$ Expected). In the case of those with $\mathrm{Hb}_{\mathrm{Alc}}$ levels more than $7.5 \%$ i.e. hyperglycemic; the trend was similar as the normal patients without depression were observed to be less in number as compared to hypothetical expected count ( $\mathrm{N}=7$ Observed, $\mathrm{N}=8.4$ Expected) and in patients with BDI II Score interpretation of moderate depression observed to be more than expected. ( $\mathrm{N}=10$ Observed, $\mathrm{N}=6.2$ Expected). The association revealed that those DM patients who had a $\mathrm{Hb}_{\mathrm{A1c}}$ level of range $6.5 \%$ to $7.5 \%$ were less depressed and those with hypoglycemia experience mild depression while hyperglycemic patients experience moderate depression for most part. The association is graphically expressed in Figure 4.

The results of all the associations are also tabulated in Table 5.

\section{DISCUSSION}

Diabetes mellitus DM is responsible for pathophysiology of various co-morbidities such as depression. The study investigated the phenomenon in Pakistan's health care system. The study incorporated 207 patients with established diagnosis of DM and investigated about 
depression as a co-morbidity using BDI II Scale. The majority of the patients encountered were geriatrics above the age of 45 years $(\mathrm{N}=139,67.1 \%)$ which is a common occurrence in old age patients in Pakistan. ${ }^{6}$ Majority of the patients were reported to be out patients. $(\mathrm{N}=142,68.6 \%)$ The females were more prone to the disease as they were seen in majority. ( $\mathrm{N}=116,56 \%)$ This finding encores the results of previous studies which also reported the same phenomenon. ${ }^{9}$ The reasons for this can be attributed to the lifestyle and elevated BMI which is also seen in Pakistani women and it is the major cause of female deaths in the country. ${ }^{14,19}$

In terms of education majority seemed to be educated to some extent. In addition, an encouraging number of patients were reported to attain graduation however slightly less than a tenth of segment was observed to be uneducated $(\mathrm{N}=26,12.6 \%)$ which pose a risk to the patients and call for extra input into their pharmacotherapy of DM. ${ }^{6,7}$ The majority of patients were married. In case of BMI, it was observed that almost a third of the target segment was normal with their BMI in range of 18-25 $\mathrm{kg} / \mathrm{m}^{2}(\mathrm{~N}=72,34.8 \%)$ and exactly the same of the target group was overweight with their BMI in range of $25-30 \mathrm{~kg} /$ $\mathrm{m}^{2}(\mathrm{~N}=72,34.8 \%)$. A small segment was also reported to have BMI greater than $30 \mathrm{~kg} / \mathrm{m}^{2}$ i.e. obese $(\mathrm{N}=56,27.1 \%)$. This finding reconfirms the fact that DM is linked with obesity which is quiet common in Pakistan and the one which is quite troublesome as its management is proving to be difficult for the health care force as well. Adequate management of obesity can help reduce the prevalence of DM in Pakistani population..$^{20,21}$

The smoking status of patients revealed that majority did not smoke $(\mathrm{N}=131,63.3 \%)$ however a third of the sample did smoke and were differentiated as rare, regular and chronic smokers. This finding is quite worrisome as smoking in diabetes mellitus is proven by a number of studies to raise the level of $\mathrm{Hb}_{\mathrm{A} 1 \mathrm{c}}$ to about $34 \%$ in blood and over the long run precipitate complications of the cardiovascular system and mortality. ${ }^{22,23}$ Hence, smoking cessation must be encouraged in such patients coupled with nicotine replacement therapy NRT as they are proven to be helpful in such cases. ${ }^{24}$

Regarding the professional information, slightly more than half of the target population were reported not working $(\mathrm{N}=113,54.6 \%)$ or associated with any employment. $(\mathrm{N}=123,59.4 \%)$ It is worthwhile mentioning here that DM also results in absence from work and decrease quality of life which could pose a threat to the employment of the affected individuals. ${ }^{25}$
In addition to this, out of the total patients surveyed for DM the major chunk comprised of DM type II patients $(\mathrm{N}=171,82.6 \%)$ followed by type $\mathrm{I}(\mathrm{N}=23,11.1 \%)$ and Gestational DM patients. (N=13, 6.3\%) The duration of disease for most part was reported to be less than 5 years $(\mathrm{N}=107,51.7 \%)$ however a third of sample was reported to suffer from the ailment since 5 to 10 years. ( $N=66,31.9 \%)$ and since more than 10 years. $(\mathrm{N}=34,16.4 \%)$ Majority had a diabetic family member $(\mathrm{N}=137,66.2 \%)$. Similar findings are also reported in earlier studies conducted in Pakistan. ${ }^{7,18,19}$

The level of glycated haemoglobin was seen adequately managed in many patients and it was reported to be in the range of $6.5 \%$ to $7.5 \%(\mathrm{~N}=111,53.6 \%)$ Majority of patients had various co-morbid conditions out of which cardiovascular complications alone and in combination with endocrine topped the list in first and second place respectively. This finding is common as a number of research literatures report that DM associated co-morbidity list is dominated by the cardiovascular and endocrine complications the world over. ${ }^{26}$

The patients were handed Beck Depression Inventory BDI II scoring questionnaire to document their responses to the close ended questions provided. Each variable carried a score all of which were added to obtain a final score. The scores interpret a clinical finding such as a score in range of 1 to 10 interpret normal condition/ no depression and score above 40 represents extreme depression. We found out that the majority of the patients had no depression $(\mathrm{N}=58,28 \%)$ followed by mild depression $(\mathrm{N}=54,26.1 \%)$ and a fifth of sample with moderate depression. $(\mathrm{N}=43$, $20.8 \%)$ Some had borderline clinical depression $(\mathrm{N}=28$, $13.5 \%)$ and few had severe depression $(\mathrm{N}=20,9.7 \%)$. Very few patients were seen to suffer from extreme episodes of the disease. $(\mathrm{N}=4,1.9 \%)$.

Further to this, statistical analysis of variables revealed some associations. Chi square $X^{2}$ test for association was employed and statistical significance was accepted at $\mathrm{P}$ values less than 0.05 . Some of the variables were seen to be associated with the BDI II Scores of patients. The BMI of patients was significantly associated with the BDI II Score (P value $<0.05$ ) which revealed that increasing BMI pose an increased likelihood of suffering from depression. This relationship is also explained by Ruiz RJ et al. in the study conducted among pregnant Hispanic women. ${ }^{12}$

Additionally, the duration of the disease was also linked to the BDI II Scores significantly. (P value $<0.01$ ) This association revealed that depression is minimal in patients 
with newly acquired DM i.e. less than 5 years but aggravates the most between 5 to 10 years of DM. However, it stagnates in patients with a long acquired DM for more than 10 years. The management of depression in the latter might be attributed to the use of antidepressants. This relationship can be explained by the fact that long term stress and occupied thoughts about the fear of disease as well as debilitating health might strain the diabetic patient coupled with micro vascular complications of the disease itself resulting in compromised brain functions finally leading to depression. Hence, according to Dr Frank $\mathrm{Hu}(\mathrm{MD}, \mathrm{PhD}, \mathrm{MPH})$ and Professor of Nutrition and Epidemiology at the Harvard School of Public Health in Boston. "There is long-term stress and strain associated with diabetes management such as blood sugar control and treatment for complications, and this can lead to decreased quality of life and increased probability of depression," Unquote.3

The family history was also significantly associated with the BDI II Scores (P value $<0.01$ ) which revealed the fact that the patients with DM having a risk factor of genetic predisposition for the disease are more prone to suffer from depression as compared to those having no genetic predisposition. This association is also established as a risk factor and confirmed by a number of studies conducted worldwide. ${ }^{10,8,11}$ The levels of glycated haemoglobin $\mathrm{Hb}_{\mathrm{A1c}}$ were seen to be statistically associated with the BDI II Scores (P value $<0.01)$ which publicized that those DM patients who had $\mathrm{Hb}_{\mathrm{Alc}}$ level of range $6.5 \%$ to $7.5 \%$ were less depressed and those with hypoglycaemia experience mild depression while hyperglycaemic patients experience moderate depression for most part. This phenomenon is explained by many experts worldwide that blood sugar level if not kept in target normal range can lead to depression. Patients with hypoglycaemia normally experience low mood while those with hyperglycaemia may experience clinical depression. ${ }^{4}$

In the developed countries such as the US, a study reported a cognitive behavioural therapy (CBT) of patients which was delivered by telephone reduced the depressive symptoms ${ }^{27}$ However, in the regional context i.e. South Asia, study emphasize on the patient education and increasing disease awareness. Keeping in view the attitudes on health care and cultural beliefs, a customized prevention and gender specific diabetes education program is highly recommended. ${ }^{28}$

\section{CONCLUSION}

Diabetes mellitus DM in Pakistan is on the rise especially among the females and is aggressively posing a risk of depression to the affected patients. To minimize the comorbid DM induced depression, DM needs to be taken care of. Cardiovascular comorbidity is the major comorbid condition reported in DM patients and severe episodes of depression are reported in patients with CVS comorbid condition alone or in combination. Moreover, social status and lifestyle of diabetic patients of Pakistan is also contributing to the increased likelihood of suffering from depression. Obesity and insufficient disease education are two major hurdles in adequate management of the DM. The country has a large population of diabetic patients which are genetically predisposed to the disease. Though genetic predisposition to DM is a non modifiable risk factor nonetheless, educating the genetically predisposed patients about the disease can prove effective in dealing with the disease and its complications since patients will be prepared and be taught aggressive self management of the disease which may also prove to be helpful in managing co-morbid depression.

\section{CONFLICT OF INTEREST}

The team of authors declare no conflicts of interests exist.

\section{AUTHOR'S CONTRIBUTION}

All authors contributed to the article in equal aspects.

\section{SUPPORTING INFORMATION}

This research paper is based on the research project undertaken as a Bachelor's thesis to be submitted as partial fulfilment in the Doctor of Pharmacy (Pharm.D) program at Faculty of Pharmacy, Ziauddin University. No funding was sought or obtained for the study.

\section{ACKNOWLEDGEMENTS}

The team of authors express their gratitude to the patients for their support. 


\section{Highlights of Paper}

- Likelihood of suffering from depression in DM is high.

- Modifiable factors i.e. BMI, HBA1c, etc. and non modifiable factors of DM such as genetic predisposition and disease duration play an important role in occurrence of depression as comorbidity.

- Educating the patients about DM can prove effective in dealing with the disease.

\section{Author Profile}

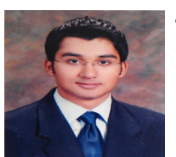

Dr. Atta Abbas is currently an Assistant Professor in the Department of Pharmacy Practice at the Hamdard Institute of Pharmaceutical Sciences, Hamdard University and Advisory Board Member at Clifton Hospital, Karachi, Pakistan. His research interests are mainly in the area of Pharmacotherapy, Public Health and Social Pharmacy.

\section{REFERENCES}

1. Micheal J. Fowler. Microvacular and Macrovascular Complications of Diabetes. Clinical diabetes 2008; 26(2): 2008.

2. Amy C, Weintrob, Daniel Sexton J. Susceptibility of infections in persons with diabetes mellitus. Uptodate 2014.

3. Denise Mann. New Links Seen Between Depression and Diabetes. Web MD. [Online] November 22, 2010. [Cited: December 27, 2014.] http://www.webmd.com/depression/news/20101122/newlinks-seen-between-depression-and-diabetes.

4. Does Diabetes Cause Depression? American Diabetes Association ADA. [Online] May 14, 2014. [Cited: December 27, 2014.] http:// www.diabetes.org/living-with-diabetes/complications/mentalhealth/depression.html.

5. Mezuk B, Johnson-Lawrence V, Lee H, Rafferty JA, Abdou CM, Uzogara EE. Is ignorance bliss? Depression, antidepressants, and the diagnosis of prediabetes and type 2 diabetes. Health Psychol. 2013; 32: 254-63.

6. Ghazala Rafique, Furqan Shaikh. Identifying needs and barriers to Diabetes Education in Patients with Diabetes. Journal of Pakistan Medical Association 2006; 56: 347-52.

7. Gul, Naheed. Knowledge, Attitudes and practices of Type II diabetic patients. Journal of Ayub Medical College 2010; 22: 128-31.

8. Family Health History and Diabetes. National Diabetes Education Program. [Online] [Cited: December 27, 2014.] http://ndep.nih.gov/ am-i-at-risk/family-history/\#main.

9. Gebel, Erika. How Diabetes Differs for Men and Women. Diabetes Forecast. [Online] Oct 2011. [Cited: Dec 27, 2014.] http://www. diabetesforecast.org/2011/oct/how-diabetes-differs-for-men-andwomen.html.

10. Genetics of Diabetes. American Diabetes Association ADA. [Online] [Cited: December 27, 2014.] http://www.diabetes.org/ diabetes-basics/genetics-of-diabetes.html.

11. Type 2 diabetes runs in the family. Australian Diabetes Council. [Online] [Cited: December 27, 2014.] http://www. australiandiabetescouncil.com/about-diabetes/type-2-diabetesruns-in-families.

12. Ruiz RJ, Stowe RP, Goluszko E, Clark MC, Tan A. The relationships among acculturation, body mass index, depression, and interleukin 1-receptor antagonist in Hispanic pregnant women. Depression 2007; 17(2): 338-43.

13. Healthcare. Pakistan ranked 7 th in diabetes prevalence. The Express Tribune. [Online] July 19, 2013. [Cited: 27 December, 2014.] http://tribune.com.pk/story/578880/healthcare-pakistanranked-7th-in-diabetes-prevalence/.

14. Pakistan ranks seventh in Diabetes population. Dawn.com. [Online] December 11, 2011. [Cited: December 27, 2014.] http://www.dawn. com/news/679741/pakistan-ranks-seventh-in-diabetes-population.

15. People suffer from diabetes in Pakistan. Daily Times. [Online] March 6, 2014. [Cited: December 27, 2014.] http://www. dailytimes. com.pk/sindh/06-Mar-2014/7-1m-people-suffer-from-diabetes-inpakistan.

16. Ali Khan Khuwaja, Saima Lalani, Raheem Dhanani, Iqbal Syed
Azam, Ghazala Rafique, et al. Anxiety and depression among outpatients with type 2 diabetes: A multi-centre study of prevalence and associated factors. Diabetology \& Metabolic Syndrome 2010; 2: 1 .

17. Areeha Faisal, Shaheen Asghar M, Zafar Iqbal Hydrie, Asher Fawwad, Abdul Basit, et al. Depression and Diabetes in HighRisk Urban Population of Pakistan. The open diabetes Journal 2010; 3: 1-5.

18. Mehwish Rizvi, Sidra Tanwir, Atta Abbas, Arif Sabah, Zeb-un-Nisa, Imran Mustaq, et al. I Epidemiological study of diabetes mellitus DM among different ethic segments of population in Pakistan. A nationwide ethnographical study. nternational Journal of Research in Pharmacology and Pharmacotherapeutics 2014; 3: 40-5.

19. Diabetes in Pakistani Women. Asian Women Magazine. [Online] [Cited: Dec 27, 2014.] http://www.asian-women-magazine.com/ women-health/diabetes.php.

20. Sadaf Shahid, Atta Abbas, Arif Sabah, Sidra Tanwir, Farrukh Rafiq Ahmed, et al. The knowledge and practices of physicians regarding pharmacotherapy of obesity: The current scenario in Pakistan. International Journal of Pharmacology and Pharmacotherapeutics 2014; 3: 53-9.

21. Sadaf Shahid, Atta Abbas. The quandary of obesity treatment and management strategy in Pakistan. Journal of Pharmacreations 2014; 1 : 29-31.

22. Diabetes and Smoking. Diabetes.co.uk. [Online] [Cited: Dec 27, 2014.] http://www.diabetes.co.uk/diabetes-and-smoking.html.

23. First identification of nicotine as main culprit in diabetes complications among smokers. American Chemical Society. [Online] March 27, 2011. [Cited: Dec 27, 2014.] http://www. acs.org/content/acs/en/pressroom/newsreleases/2011/march/ first-identification-of-nicotine-as-main-culprit-in-diabetescomplications-among-smokers.html.

24. Benjamin Apelberg J, Georgiana Onicescu, ScM, Erika Avila-Tang and Jonathan $\mathrm{M}$, et al. Estimating the Risks and Benefits of Nicotine Replacement Therapy for Smoking Cessation in the United States. American Journal of Public Health 2010; 100: 341-8.

25. Mudassar Hussain, Syed Baqar Shyum Naqvi, Maqsood Ahmed Khan, Mehwish Rizvi, et al. Direct cost of treatment of diabetes mellitus type II in Pakistan. International Journal of Pharmacy and Pharmaceutical Sciences 2014; 6: 261-4.

26. Management of Common Comorbidities of Diabetes. AACE Diabetes Resource Centre. [Online] [Cited: December 27, 2014.] http://outpatient.aace.com/type-2-diabetes/management-ofcommon-comorbidities-of-diabetes.

27. Richardson C, Himle J, Duffy S, Torres T, Vogel M, Barber K, et al. A randomized trial of telephonic counseling plus walking for depressed diabetes patients. Piette J Med Care. 2011; 49(7): 641-8.

28. Sarita Bajaj, Fatema Jawad, Najmul Islam, Hajera Mahtab, Jyoti Bhattarai, et al. South Asian women with diabetes: Psychosocial challenges and management: Consensus statement. Indian J Endocrinol Metab. 2013; 17(4): 548-62.

Journal of Young Pharmacists Vol $7 \bullet$ Issue $3 \bullet$ Jul-Sep 2015 